\title{
Keyhole retrosigmoid approach for large vestibular schwannomas: strategies to improve outcomes
}

\author{
Reid Hoshide, MD, MPH, ${ }^{1,2}$ Harrison Faulkner, ${ }^{1,3}$ Mario Teo, MBChB, FRCS(SN), ${ }^{1,4}$ and \\ Charles Teo, MBBS, FRACS ${ }^{1}$
}

${ }^{1}$ Centre for Minimally Invasive Neurosurgery, Prince of Wales Private Hospital; ${ }^{3}$ Faculty of Medicine, University of New South Wales, Sydney, Australia; ${ }^{2}$ Department of Neurosurgery, University of California, San Diego, California; and ${ }^{4}$ Department of Neurosurgery, North Bristol University Hospital, Bristol, United Kingdom

\begin{abstract}
OBJECTIVE There are numerous treatment strategies in the management for large vestibular schwannomas, including resection only, staged resections, resections followed by radiosurgery, and radiosurgery only. Recent evidence has pointed toward maximal resection as being the optimum strategy to prevent tumor recurrence; however, durable tumor control through aggressive resection has been shown to occur at the expense of facial nerve function and to risk other approach-related complications. Through a retrospective analysis of their single-institution series of keyhole neurosurgical approaches for large vestibular schwannomas, the authors aim to report and justify key techniques to maximize tumor resection and reduce surgical morbidity.
\end{abstract}

METHODS A retrospective chart review was performed at the Centre for Minimally Invasive Neurosurgery. All patients who had undergone a keyhole retrosigmoid approach for the resection of large vestibular schwannomas, defined as having a tumor diameter of $\geq 3.0 \mathrm{~cm}$, were included in this review. Patient demographics, preoperative cranial nerve status, perioperative data, and postoperative follow-up were obtained. A review of the literature for resections of large vestibular schwannomas was also performed. The authors' institutional data were compared with the historical data from the literature.

RESULTS Between 2004 and 2017, 45 patients met the inclusion criteria for this retrospective chart review. When compared with findings in a historical cohort in the literature, the authors' minimally invasive, keyhole retrosigmoid technique for the resection of large vestibular schwannomas achieved higher rates of gross-total or near-total resection (100\% vs $83 \%$ ). Moreover, these results compare favorably with the literature in facial nerve preservation (House-Brackmann I-II) at follow-up after gross-total resections ( $81 \%$ vs $47 \%, p<0.001)$ and near-total resections $(88 \%$ vs $75 \%, p=0.028)$. There were no approach-related complications in this series.

CONCLUSIONS It is the experience of the senior author that complete or near-complete resection of large vestibular schwannomas can be successfully achieved via a keyhole approach. In this series of 45 large vestibular schwannomas, a greater extent of resection was achieved while demonstrating high rates of facial nerve preservation and low approachrelated and postoperative complications compared with the literature.

https://thejns.org/doi/abs/10.3171/2017.11.FOCUS17607

KEY WORDS vestibular schwannoma; retrosigmoid approach; keyhole craniotomy; hearing preservation

$\mathrm{V}$ ESTIBULAR schwannomas are typically histopathologically benign tumors that arise from the vestibular branches of cranial nerve (CN) VIII. Vestibular schwannomas have an incidence of approximately 1:100,000 per year in the population of the US and Europe. ${ }^{8,28}$ Despite the benign nature of these lesions, vestibular schwannomas have a tendency to grow at insidious rates, which if left untreated may result in compression of CNs, sensitive vasculature, and brainstem structures.
The consequence of this compression can lead to tinnitus, hearing loss, facial sensory changes, cerebellar dysfunction, or hydrocephalus.

With increasing understanding of the natural history of vestibular schwannomas and the development of various treatment strategies, the management for these tumors has evolved over time. Many treatment paradigms focus on certain characteristics, such as patient age, symptoms, and tumor size, to determine the best treatment strategy.

ABBREVIATIONS $\mathrm{CN}=$ cranial nerve; $\mathrm{CPA}=$ cerebellopontine angle; $\mathrm{HB}=$ House-Brackmann; $\mathrm{IAM}=$ internal auditory meatus .

SUBMITTED September 26, 2017. ACCEPTED November 16, 2017.

INCLUDE WHEN CITING DOI: 10.3171/2017.11.FOCUS17607. 
Currently, for small and medium-sized asymptomatic vestibular schwannomas, the "watch and wait" approach has been used because several studies have shown that the majority of cases do not grow, and 8\%-16\% could actually regress. ${ }^{5,24,38,42}$ Interventions would be considered if tumor growth of $\geq 2 \mathrm{~mm} /$ year were detected. ${ }^{23,39}$ Although microsurgical resection and radiation therapy are viable options, the outcomes of vestibular schwannomas treated by radiosurgery are rapidly improving, with 4 nonrandomized prospective studies demonstrating that radiosurgery outcomes were either better than or similar to those obtained with resection. 22,26,27,32 Apart from good long-term tumor control ranging between $90 \%$ and $97 \%$ at 5 years, facial nerve and functional hearing preservation were shown to be greater with radiosurgery compared with surgical alternatives. ${ }^{26,31,32}$ Therefore, microsurgical resection of small or medium-sized vestibular schwannomas is becoming less frequent.

Conversely, large vestibular schwannomas, defined as being $>3 \mathrm{~cm}$ in their largest diameter, commonly present with chronic, symptomatic brainstem compression, and for this reason alone are better managed with resection. Additionally, many expert radiation oncologists consider any tumor $>3.0 \mathrm{~cm}$ in diameter to be a relative contraindication to radiation. Therefore, the goals of treatment for large vestibular schwannoma usually include safe tumor resection, brainstem decompression, preservation of facial nerve function, minimal postoperative morbidity, and preservation of serviceable hearing, if present preoperatively.

Many treatment strategies have been proposed to achieve these aims, including different surgical approaches, staged tumor resection, and subtotal resection with postoperative radiosurgery.

Keyhole surgical approaches to brain tumors are rapidly gaining popularity given the reduced operating times for opening and closing, the reduced morbidity, and the excellent results. The keyhole retrosigmoid craniotomy is one such approach that, when done well, aims to reduce operating time and postoperative morbidity. It can also provide outstanding access to the entire ventrolateral brainstem and cerebellopontine angle (CPA), with reduced approach-related morbidity. Surgical concerns include brain herniation with dural opening, damage to the ipsilateral cerebellar hemisphere with retraction during the tumor resection, cranial neuropathies (other than of CNs VII and VIII), vascular injury, postoperative CSF leak and infection, and chronic headache as a late sequela. A keyhole approach to the CPA reduces the unnecessary exposure of neural elements that could otherwise be inadvertently at risk for injury or desiccation. The planning for the keyhole approach, from the planning of the incision, craniotomy, and trajectory, also reduces the need for injurious retraction. There is a misconception that the keyhole approach is synonymous with a smaller craniotomy, which is untrue; a keyhole approach is an optimized surgical access to pathological entities. Given that fact, all preoperative images need to be studied well to personalize an approach to tumor resection-not all tumors are the same. Tumor size, location, surrounding structures, tumor projections, and line of sight in the approach are all important factors to which special attention must be paid because they determine the operative approach for tumor resection.

In this report, we present our single-institution experience with the resection of large vestibular schwannomas via a keyhole retrosigmoid craniotomy. We then summarize the strategies developed for clinical outcome, and compare our results with those of the relevant literature.

\section{Methods}

A prospectively maintained database of all patients who were surgically treated by the senior surgeon (C.T.) was used to identify large vestibular schwannomas resected via a keyhole retrosigmoid approach between 2004 and 2017. The definition for large vestibular schwannomas was a diameter $>3.0 \mathrm{~cm}$ in any dimension radiographically. Supplementary clinical information was obtained, and retrospective chart review, radiological review of preand postoperative MR images, and latest follow-up from clinical consultation or electronic correspondence were required for inclusion. The categories for extent of resection were defined as gross-total resection (no radiographic evidence of residual tumor), near-total resection $(>90 \%$ resection of tumor), and subtotal resection ( $\leq 90 \%$ resection of tumor) as described by the clinical radiologist.

For a comparison of the existing data, online PubMed and MEDLINE queries were conducted of articles written in the English language that were published between January 1970 and May 2017, by using a combination of search terms, including "vestibular schwannoma" and "acoustic neuroma." The search, which was conducted most recently on May 30, 2017, was supplemented by manually reviewing reference lists from the identified publications. Articles selected for review were based on adequacy of preoperative, perioperative, and postoperative data; patient characteristics; surgical approach; pathological diagnosis; adjuvant treatment; and overall manuscript quality. Only surgical series with a defined minimum tumor diameter of $3.0 \mathrm{~cm}$ were included in the pooled analysis. A total of 1239 tumor resections were reported in English-language journals between January 1970 and May 2017.

\section{Operative Technique}

Patients are positioned supine with the head fixed in a Mayfield head holder, with the head rotated maximally to the contralateral side, without obstructing the jugular venous drainage (Fig. 1).

The head is elevated to encourage venous return, and to maximize the surgeon's view without obstruction from large-shouldered patients. The patient's body is also secured to the bed to allow for significant tilt or reverse Trendelenburg position when petrous or tentorial visualization is required. Facial nerve monitoring is applied, with traditional monitoring of both the orbicularis oris and orbicular oculus muscle groups with spontaneous and triggered electromyography. Frameless neuronavigation is then set up to accurately identify the transverse-sigmoid junction, because placement of the incision and craniotomy is of paramount importance in performing a keyhole retrosigmoid craniotomy. Typically, an oblique linear incision is used after identifying the accurate and precise size and 


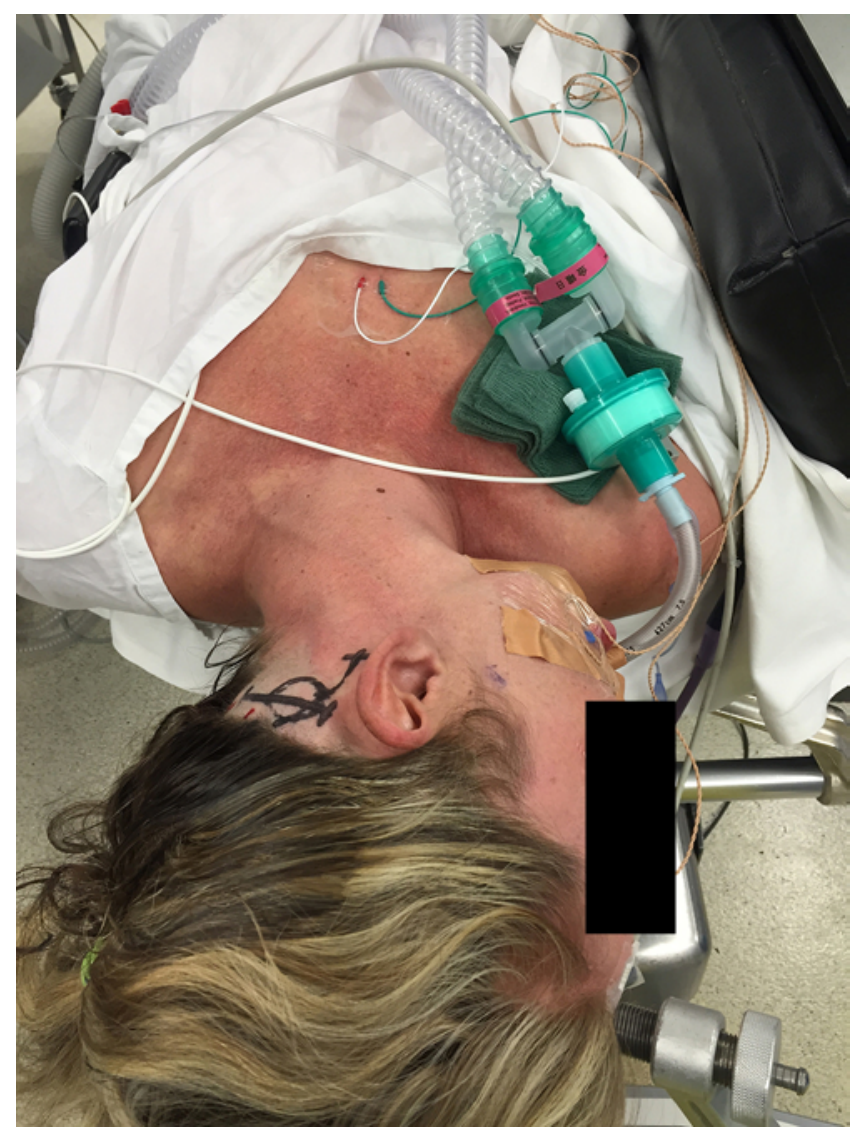

FIG. 1. Patient positioning and incision planning are vital. The head is turned maximally away from the incision. The shoulders are depressed downward as far as possible to prevent obstruction. The head is elevated and flexed as much as possible to move the incision as far away from the shoulder as possible. The head of the operative table is attached to the contralateral bed rail (as seen in the upper left-hand corner) to secure the patient on the table even with aggressive table tilting.

location of the keyhole craniotomy to be performed. The orientation of the incision is important in placement of the self-retaining retractor so that the blades of the retractor do not obstruct the surgeon's passage of instruments.

A keyhole retrosigmoid craniectomy is drilled with a cutting burr, and a V-shaped dural opening is made with its base at the sigmoid sinus. Once the durotomy has been made, the cerebellar surface is protected with a cotton patty and gently retracted to expose the petrous surface. The traditional teaching for retrosigmoid craniotomy is to obtain brain relaxation and retraction by obtaining a large bony exposure to the cisterna magna to allow CSF drainage after dural opening. However, in our experience CSF drainage via the lateral medullary cistern was sufficient in obtaining both drainage and subsequent cerebellar relaxation without the need for a fixed retraction system.

Once the surgeon reaches the brainstem and the tumor itself, it is important to probe the tumor surface for the facial nerve to avoid inadvertent injury to the nerve during the stages of tumor debulking. Naturally, the large size of the tumor could create a flattened appearance of the facial nerve, mimicking fibers of the tumor capsule or arachnoid. Once the tumor bulk has been encountered, the posterior

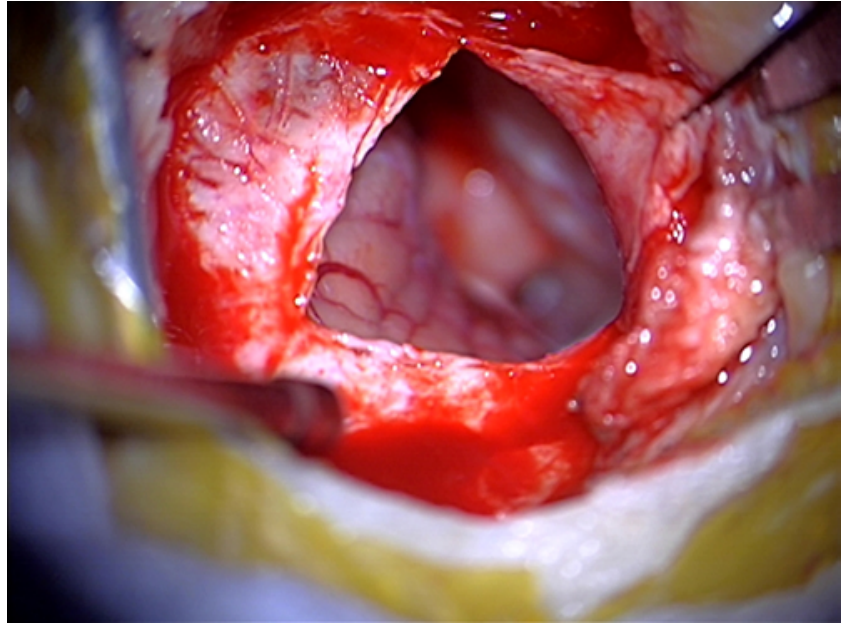

FIG. 2. Postoperative view of the tumor resection cavity, showing the degree of visualization by this keyhole approach-with the dural opening as minimal as needed to expose the operative corridor, the craniotomy as minimal as needed to expose the dural opening, and the skin incision as minimal as needed to expose the craniotomy.

aspect of the lesion is stimulated liberally to confirm that the facial nerve is not located on this surface. A window is cut in the tumor capsule, and tumor debulking is performed with cautery, suction, piecemeal removal, or ultrasonic aspiration. Routinely, the tumor capsule can then be manipulated externally to free the attachments from the nearby structures. This may also uncover vital structures, such as CNs and vital vascular structures. Commonly, the facial nerve is identified on the inferior aspect of the tumor at its root entry zone. Unless the facial nerve and tumor plane is easily developed without devascularizing the nerve, we accept leaving a layer of tumor along the attenuated facial nerve-the nerve's preservation would be more important than a gross-total resection.

For soft tumors with minor extension into the internal auditory meatus (IAM), this can be removed with endoscopic guidance, to avoid the morbidity associated with IAM drilling. Even with endoscopic visualization, in larger vestibular schwannomas, or those that extend to the apex of the IAM, drilling is required to ensure identification of the distal facial nerve and maximal tumor removal. Finally, endoscopic inspection of the drilled IAM can be used to look for air cells and for microsurgical inspection of the edges of the cranial opening to ensure that all exposed mastoid air cells are occluded. Figure 2 demonstrates the cavity left behind after complete tumor resection and thorough hemostasis. The elements of a keyhole craniotomy are highlighted here: a minimal dural opening to achieve maximal tumor resection, a minimal craniotomy to obtain the necessary dural exposure, and a minimal skin incision to obtain the necessary craniotomy exposure. A watertight dural closure is then performed, with multilayer wound closure (Fig. 3).

\section{Results}

Between the years 2004 and 2017, a total of 45 patients met the inclusion criteria in this retrospective review. The 


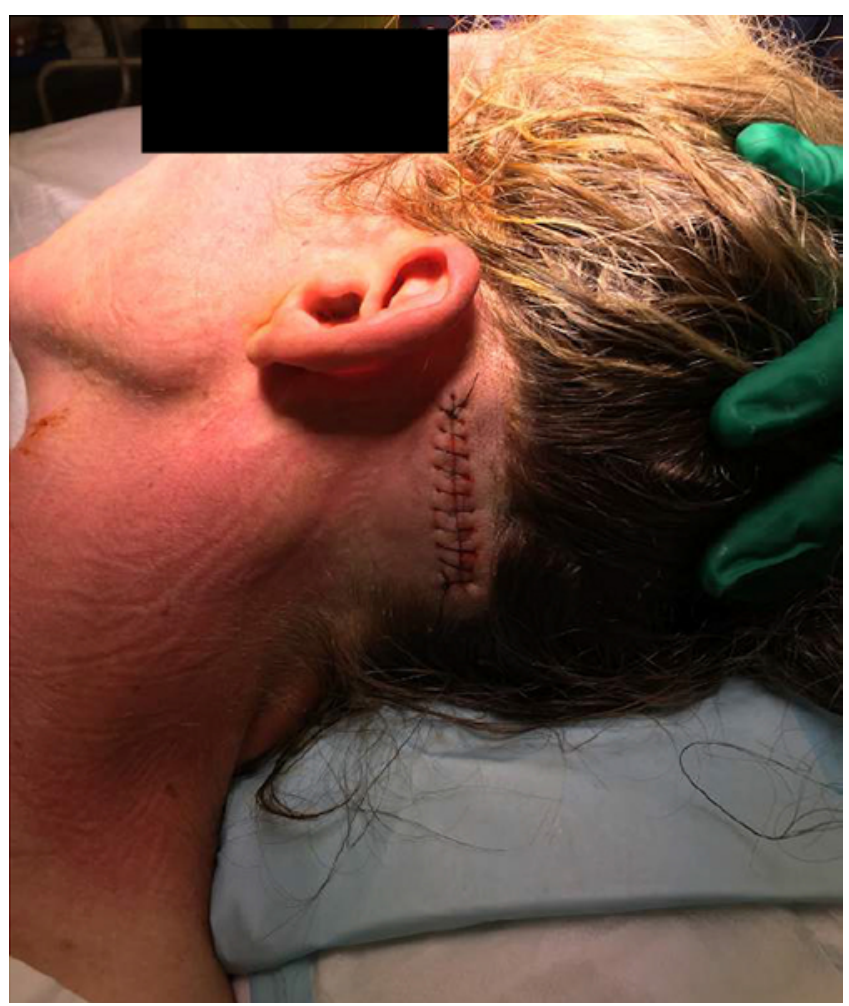

FIG. 3. The incision, now closed, exemplifying the simplicity yet versatility of the incision for a keyhole retrosigmoid approach for large vestibular schwannomas.

characteristics of the study population are displayed in Table 1 . Our patient pool had a median age of 44 years (range 20-67 years) and a 53\% female distribution. All patients had large vestibular schwannomas, which were defined as having a diameter $>3.0 \mathrm{~cm}$, with a mean maximum tumor diameter of $4.4 \mathrm{~cm}$ (range $3.0-7.5 \mathrm{~cm}$ ). Complete or near-complete resection was achieved in all cases by using a keyhole retrosigmoid approach as described above. The mean clinical and radiographic follow-up period was 49 months (range 14-145 months). There were no procedures that did not apply the keyhole principles-all surgeries performed for large vestibular schwannomas were achieved via a keyhole craniotomy.

The most common presenting symptoms were subjective hearing loss (78\%), facial numbness (56\%), imbalance (33\%), and dizziness or vertigo (33\%). The mean duration of symptom onset was 3 years (range 1 month-20 years).

All patients except one had normal facial function preoperatively. This one patient had a House-Brackmann (HB) II weakness prior to surgery. Postoperatively, nearly $40 \%$ experienced transient facial weakness. On follow-up, good facial function (HB I-II) was observed in 38 patients (84\%), with fair (HB III) and poor (HB IV-V) in $9 \%$ and $7 \%$ of cases, respectively. There were no cases of HB VI paralysis postoperatively. Of the 8 patients with serviceable hearing preoperatively, $3(37.5 \%)$ had functional hearing (Gardner-Robertson I-II) postoperatively.

No intraoperative complications were experienced in this series. Specifically, there were no cases of brain herniation with dural opening, damage to the cerebellar
TABLE 1. Characteristics of 45 patients in our single-institution database from 2004 to 2017

\begin{tabular}{|c|c|}
\hline Variable & Value \\
\hline \multicolumn{2}{|l|}{ Age (yrs) } \\
\hline Mean & 48 \\
\hline Median & 44 \\
\hline Range & $20-67$ \\
\hline \multicolumn{2}{|l|}{ Sex $(\%)$} \\
\hline Male & 47 \\
\hline Female & 53 \\
\hline Neurofibromatosis (\%) & 4 \\
\hline \multicolumn{2}{|l|}{ Presenting symptoms (\%) } \\
\hline Hearing loss & 78 \\
\hline Facial numbness & 56 \\
\hline Imbalance & 33 \\
\hline Dizziness or vertigo & 33 \\
\hline \multicolumn{2}{|l|}{ Duration of symptoms (mos) } \\
\hline Mean & 40 \\
\hline Median & 24 \\
\hline Range & $1-240$ \\
\hline \multicolumn{2}{|l|}{ Maximum tumor diameter (cm) } \\
\hline Mean & 4.4 \\
\hline Median & 4 \\
\hline Range & $3.0-7.5$ \\
\hline \multicolumn{2}{|l|}{ Extent of resection (\%) } \\
\hline Total or near total & 100 \\
\hline Required drilling of the IAM & 5 \\
\hline \multicolumn{2}{|c|}{ Facial nerve function at follow-up (\%) } \\
\hline HB I-II & 84 \\
\hline HB III & 9 \\
\hline HB IV-V & 7 \\
\hline \multicolumn{2}{|l|}{ Follow-up (mos) } \\
\hline Mean & 49 \\
\hline Median & 38 \\
\hline Range & $14-145$ \\
\hline
\end{tabular}

hemisphere, or need for fixed retraction of the cerebellum. There were no postoperative complications, such as intracranial hemorrhage and unexpected $\mathrm{CN}$ deficit (CNs VII and VIII excepted). At long-term follow-up there were no cases of chronic headache. No patients required reoperation for tumor recurrence. Figure 4 demonstrates a large, left-sided vestibular schwannoma with a small IAM component. This tumor was resected using keyhole principles with endoscopic assistance to achieve a gross-total resection, which included portions of tumor within the IAM. Figure 5 represents a large, right-sided vestibular schwannoma. Although a large portion of the tumor was removed using keyhole techniques, the IAM portion was unable to be addressed due to heavy involvement of tumor with the facial and cochlear nerves. Cranial nerve preservation is paramount in these circumstances, and that being the case, a near-total resection was accepted. 

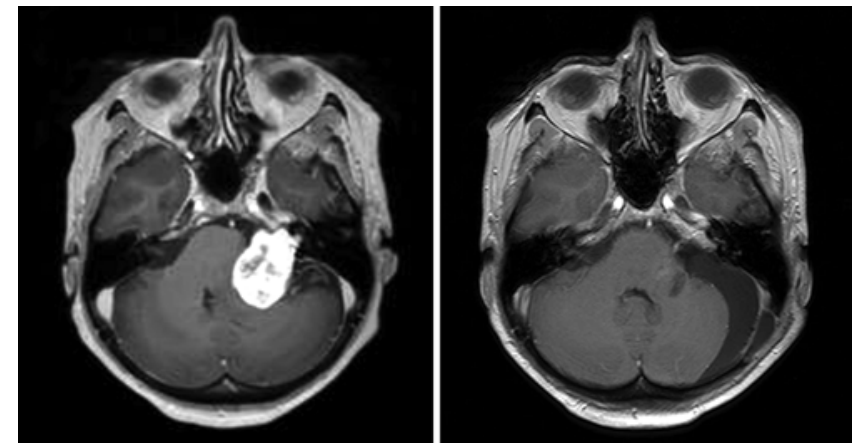

FIG. 4. Left: Preoperative axial T1-weighted MR image obtained with gadolinium contrast demonstrating a large, left-sided vestibular schwannoma with a portion of the tumor extending into the IAM. The endoscope was used in this procedure to gain angled visualization to the tumor entering the IAM. Right: Postoperative axial T1-weighted MR image obtained with gadolinium contrast demonstrating a gross-total resection of this tumor, 3 months after surgery.

On review of the literature, we found 23 uniquely published series that met the criteria for resection of large vestibular schwannomas, which are listed in Table 2. The reporting of follow-up and outcome data was thorough and complete. Aspects of the studies included tumor size, surgical approach, extent of resection, and postoperative facial nerve function.

Many of these studies were similarly examined in a 2012 pooled analysis by Gurgel et al.. ${ }^{14}$ which found good facial nerve outcomes (HB I-II) produced in $65.2 \%$ of the 601 retrosigmoid approaches. The extent of surgical resection was reported in 471 patients (Table 3 ). Of the 80 patients with subtotal resection, $92.5 \%$ had good facial nerve outcomes at an average of 12 months of follow-up, compared with $74.5 \%$ of the 55 who received near-total resections and $47 \%$ of the 336 who received gross-total resections. For patients with near-total resections, $75 \%$ had an HB score of I-II at follow-up, which compared with our institution's $88 \%(p=0.028)$. Gross-total resections led to only $47 \%$ of patients with HB I-II at follow-up, which compared with our $81 \%(\mathrm{p}<0.001)$. Gurgel et al. concluded that subtotal resections were better than near-total resections (OR 4.21, 95\% CI 1.50-11.79; $\mathrm{p}=0.004$ ), and near-total resections were significantly better than grosstotal resections (OR 3.26, 95\% CI 1.71-6.20; $p=0.0002$ ) in producing better facial nerve outcomes. No follow-up data were reported with regard to tumor or symptomatic recurrence, however. No patients in our series underwent subtotal resection.

\section{Discussion}

Although surgery is widely accepted as the treatment modality of choice for large vestibular schwannomas, certain aspects of the strategy remain challenging. Variations in surgical approach, staging of tumor resection, and postoperative radiosurgery have been proposed to achieve superior results while respecting the need for maximal tumor resection, brainstem decompression, facial nerve preservation, and long-term tumor remission. $1,9,14,30,34$

The literature clearly demonstrates the superiority of
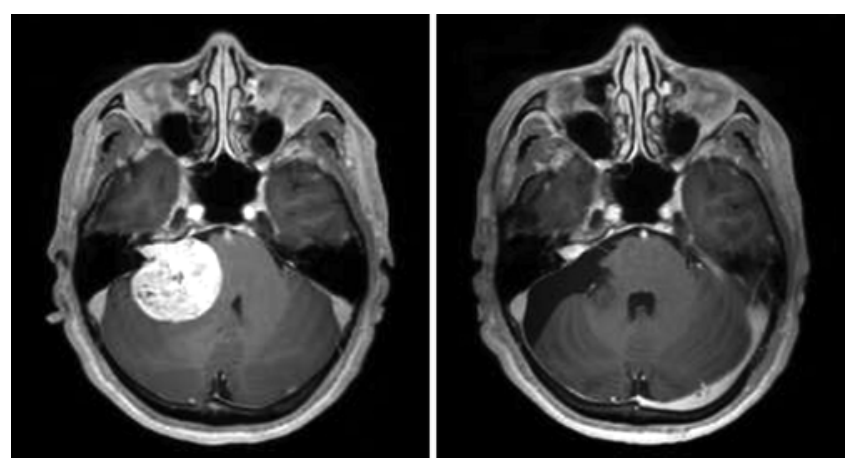

FIG. 5. Left: Preoperative axial T1-weighted MR image obtained with gadolinium contrast demonstrating a large, right-sided vestibular schwannoma with a portion of the tumor extending into the IAM. In this case, the facial nerve was involved in the tumor, which made dissection difficult and dangerous for the preservation of facial nerve function. Right: Postoperative axial T1-weighted MR image obtained with gadolinium contrast demonstrating a near-total resection of this tumor, 3 months after surgery.

the standard retrosigmoid or translabyrinthine approaches in preserving facial nerve function. ${ }^{14}$ Our series supports this hypothesis, and demonstrates for the first time the feasibility of achieving these results by using keyhole techniques. Indeed, when compared with the literature, the minimally invasive approach used in our cohort yielded greater degrees of resection and long-term tumor control while maintaining good facial nerve preservation rates, without an associated increase in approach-related or postoperative complications. In fact, the postoperative complication rate in our series is significantly less than those reported in the literature ( $0 \%$ compared with a $3.2 \%$ incidence of definitive neurological complications in the largest series in the literature ${ }^{6}$ ). Of note, the chronic postcraniectomy headache associated with retrosigmoid craniectomies described by Wait et al. ${ }^{46}$ was absent among our patients. A possible basis for this success is the avoidance of a large dural exposure and subsequent adhesion to the paraspinous muscles of the occiput. ${ }^{36}$

Studies have shown that the best strategy for tumor control is to achieve a high level of tumor resection while being mindful of facial nerve function ${ }^{41}$ A single-institution series from Samii et al. ${ }^{34}$ showed that of 50 patients with large vestibular schwannomas treated with gross-total resection, $92 \%$ had anatomical preservation of the facial nerve. At their last follow-up, $75 \%$ of patients had excellent or good facial nerve function, $19 \%$ had fair function, and $6 \%$ had poor function. Although radiosurgery has been reported to produce similar facial nerve outcomes for Koos grade 3 tumors (mean volume $9 \mathrm{~cm}^{3}$ ), its role in the context of large vestibular schwannomas remains controversial and it may be indicated only in patients with minimal symptoms of brainstem compression, surgical contraindications, or significant residual tumor mass despite attempted debulking. $4,15,25,41,43,44,47,50$

A proposal to stage large vestibular schwannomas between 2 surgeries has been shown to improve facial nerve outcome and morbidity. ${ }^{30}$ Staging the tumor resection was decided intraoperatively if there was cerebellar or 
TABLE 2. Review of the relevant literature, reporting sample size, tumor size, facial nerve outcome, recurrence, and follow-up

\begin{tabular}{|c|c|c|c|c|c|c|}
\hline Authors \& Year & No. of Pts & Size Cutoff (cm) & Mean Size $(\mathrm{cm})$ & Facial Nerve Outcome & Recurrence & Follow-Up (mos) \\
\hline Roland et al., 2004 & 56 & 3.0 & 3.7 & $\begin{array}{l}\text { HB I-III: } 90 \% \\
\text { HB I-II or better: } 84 \%\end{array}$ & $11 \%$ & Mean 29 , range $15-51$ \\
\hline Samii et al., 2010 & 50 & 4.0 & 4.4 & $\begin{array}{l}\text { HB I-III: } 75 \% \\
\text { HB IV: } 19 \% \\
\text { HB V: } 6 \%\end{array}$ & $6 \%$ & Mean 34 , range 5-62 \\
\hline Anderson et al., 2005 & 71 & 3.0 & 3.8 & $\begin{array}{l}\text { HB I-III: } 85 \% \\
\text { HB IV: } 4 \% \\
\text { HB V-VI: } 11 \%\end{array}$ & $1 \%$ & 6 \\
\hline Angeli et al., 2011 & 88 & 4.0 & NA & HB I-III: $75 \%$ & NR & $>12$ \\
\hline Charpiot et al., 2010 & 123 & 4.0 & NA & $\begin{array}{l}\text { HB I-III: } 68.5 \% \\
\text { HB IV-VI: } 31.5 \%\end{array}$ & NR & $>12$ \\
\hline Iwai et al., 2003 & 14 & 3.0 & NA & HB I-II: $85.7 \%$ & NR & Mean 32 , range $12-72$ \\
\hline Fuentes et al., 2008 & 8 & 3.5 & 3.9 & HB I-II: $87.5 \%$ & NR & $>12$ \\
\hline Lanman et al., 1999 & 95 & 3.0 & 3.6 & $\begin{array}{l}\text { HB I-II: } 52.6 \% \\
\text { HB I-IV: } 81 \% \\
\text { HB V-VI: } 18.9 \%\end{array}$ & NR & $>12$ \\
\hline Jung et al., 2000 & 30 & 4.0 & 4.92 & $\begin{array}{l}\text { HB I-III: } 84.2 \% \\
\text { HB IV: } 15.8 \%\end{array}$ & NR & $>12$ \\
\hline Mamikoglu et al., 2002 & 81 & 3.0 & 3.7 & $\begin{array}{l}\text { HB I-II: } 45 \% \\
\text { HB I-IV: } 80 \%\end{array}$ & NR & $>12$ \\
\hline Raftopoulos et al., 2005 & 13 & 3.0 & NA & $\begin{array}{l}\text { HB I-II: } 94 \% \\
\text { HB IV: } 6 \%\end{array}$ & NR & $>12$ \\
\hline Sanna et al., 2004 & 122 & 3.0 & 3.5 & $\begin{array}{l}\text { HB I-III: } 80 \% \\
\text { HB IV-VI: } 20 \%\end{array}$ & NR & $>12$ \\
\hline Wu \& Sterkers, 2000 & 40 & 3.0 & 4.25 & $\begin{array}{l}\text { HB I-II: } 65 \% \\
\text { HB III-IV: } 35 \%\end{array}$ & $3 \%$ & $>12$ \\
\hline Yamakami et al., 2004 & 50 & 3.0 & 4.1 & HB I-II: $84 \%$ & $8 \%$ & Mean 58 , range $12-115$ \\
\hline Zhao et al., 2010 & 89 & 4.0 & NA & $\begin{array}{l}\text { HB I-II: } 54 \% \\
\text { HB III-IV: } 26 \% \\
\text { HB V-VI: } 20 \%\end{array}$ & $3 \%$ & $>12$ \\
\hline Silva et al., 2012 & 29 & 4.0 & NA & $\begin{array}{l}\text { HB I-II: } 45 \% \\
\text { HB III: } 27 \% \\
\text { HB IV: } 20 \% \\
\text { HB V-VI: } 8 \%\end{array}$ & NR & Mean 39 , range 4-73 \\
\hline van de Langenberg et al., $2011^{43}$ & 42 & 3.0 & NA & HB I-II: 94\% & $10 \%$ & $>12$ \\
\hline Darwish et al., 2005 & 32 & 3.0 & NA & $\begin{array}{l}\text { HB I-II: } 22 \% \\
\text { HB III-IV: } 37 \% \\
\text { HB V-VI: } 41 \%\end{array}$ & $6 \%$ & $>12$ \\
\hline Lee et al., 2002 & 36 & 3.0 & NA & $\begin{array}{l}\text { HB I-II: } 67 \% \\
\text { HB III-IV: } 31 \% \\
\text { HB V-VI: } 2 \%\end{array}$ & $6 \%$ & Mean 24 , range $3-58$ \\
\hline Veronezi et al., 2008 & 5 & 4.0 & NA & $\begin{array}{l}\text { HB I-II: } 40 \% \\
\text { HB V-VI: } 60 \%\end{array}$ & NR & $>18$ \\
\hline Raslan et al., 2012 & 47 & 3.0 & 3.9 & HB I-II: $70 \%$ & $0 \%$ & Mean 30 \\
\hline Liu et al., 2015 & 106 & 3.0 & 3.9 & $\begin{array}{l}\text { HB I-II: } 79 \% \\
\text { HB III-IV: } 21 \%\end{array}$ & $0 \%$ & 24 \\
\hline Georges et al., 2016 & 26 & 3.0 & 3.6 & $\begin{array}{l}\text { HB I-II: } 81 \% \\
\text { HB III-IV: } 15 \% \\
\text { HB V: } 4 \%\end{array}$ & $19 \%$ & Mean 66 \\
\hline
\end{tabular}

NA = not available; NR = not reported; pts = patients. 
TABLE 3. Facial nerve outcome by degree of resection, as reported in the pooled historical analysis and our single-institution analysis

\begin{tabular}{lcccccc}
\hline & \multicolumn{2}{c}{ No. of Pts } & & \multicolumn{4}{c}{ HB I-II Facial Nerve Outcomes (\%) } \\
\cline { 2 - 3 } \cline { 6 - 7 } $\begin{array}{l}\text { Degree of } \\
\text { Resection }\end{array}$ & $\begin{array}{c}\text { Gurgel et } \\
\text { al., 2012 }\end{array}$ & $\begin{array}{c}\text { Stesent } \\
\text { Study }\end{array}$ & & $\begin{array}{c}\text { Gurgel et } \\
\text { al., 2012 }\end{array}$ & $\begin{array}{c}\text { Present } \\
\text { Study }\end{array}$ & $\begin{array}{c}\mathrm{p} \\
\text { Value }\end{array}$ \\
\hline Subtotal & 80 & 0 & & 93 & 0 & \\
\hline Near total & 55 & 16 & & 75 & 88 & 0.028 \\
\hline Gross total & 336 & 29 & & 47 & 81 & $<0.001$ \\
\hline
\end{tabular}

brainstem edema, excessive tumor adherence to the facial nerve or brainstem, a poorly stimulating facial nerve, or a thinned or splayed facial nerve. During the first stage, a retrosigmoid approach (without meatal drilling) was performed to remove the CPA portion of the tumor and decompress the brainstem. The second stage consisted of a translabyrinthine approach at a later date to remove the remaining distal portions of the tumor. A retrospective comparative cohort study by Raslan et al. ${ }^{30}$ demonstrated improved postoperative facial nerve function and greater degrees of resection in 2-stage cases as compared with single-stage operations. These cases, however, were only indicated for patients without serviceable hearing.

The extent of resection is another important factor, with several studies demonstrating significantly lower rates of recurrence with complete or near-complete resections compared with subtotal or partial debulking. ${ }^{7,40}$ For patients with partial or subtotal tumor resection, residual tumor thickness ( $7 \mathrm{~mm}$ or thicker) on postoperative MRI and the MIB-1 index are important predictors of regrowth. ${ }^{12}$

In this series, comparable facial nerve preservation rates, greater tumor resection rates, lower surgical morbidity rates, and long-term tumor control were achieved without the need for a standard craniotomy or craniectomy, or a second operation. This was achieved by ensuring strategic patient positioning; use of smaller, tailored incisions; use of neuronavigation to confirm the ideal location of the skull opening; no use of fixed retractors; early and liberal use of facial nerve monitoring; and endoscopic visualization of the IAM if necessary. These strategies for keyhole neurosurgery have been demonstrated to lead to excellent outcomes.

\section{Conclusions}

This is the first series to demonstrate the feasibility of removing large vestibular schwannomas by using keyhole techniques. With the parameters of facial nerve preservation, degree of tumor resection, postoperative morbidity, and long-term tumor control, the keyhole retrosigmoid approach offers comparable and, in some areas, superior results when compared with those of historical trials. In our single-institution series, complete and near-complete tumor resections were achieved in all patients, with $84 \%$ of patients having good facial nerve function (HB I-II) postoperatively, no surgical morbidity, and excellent longterm tumor control.

\section{References}

1. Anaizi AN, Gantwerker EA, Pensak ML, Theodosopoulos PV: Facial nerve preservation surgery for Koos grade 3 and 4 vestibular schwannomas. Neurosurgery 75:671-677, 2014

2. Anderson DE, Leonetti J, Wind JJ, Cribari D, Fahey K: Resection of large vestibular schwannomas: facial nerve preservation in the context of surgical approach and patientassessed outcome. J Neurosurg 102:643-649, 2005

3. Angeli RD, Piccirillo E, Di Trapani G, Sequino G, Taibah A, Sanna M: Enlarged translabyrinthine approach with transapical extension in the management of giant vestibular schwannomas: personal experience and review of literature. Otol Neurotol 32:125-131, 2011

4. Casentini L, Fornezza U, Perini Z, Perissinotto E, Colombo F: Multisession stereotactic radiosurgery for large vestibular schwannomas. J Neurosurg 122:818-824, 2015

5. Charabi S, Tos M, Thomsen J, Charabi B, Mantoni M: Vestibular schwannoma growth: the continuing controversy. Laryngoscope 110:1720-1725, 2000

6. Charpiot A, Tringali S, Zaouche S, Ferber-Viart C, Dubreuil $\mathrm{C}$ : Perioperative complications after translabyrinthine removal of large or giant vestibular schwannoma: outcomes for 123 patients. Acta Otolaryngol 130:1249-1255, 2010

7. Chen Z, Prasad SC, Di Lella F, Medina M, Piccirillo E, Taibah A, et al: The behavior of residual tumors and facial nerve outcomes after incomplete excision of vestibular schwannomas. J Neurosurg 120:1278-1287, 2014

8. Cohen RJ: Acoustic neuroma: summary of the NIH consensus. Md Med J 41:1128-1130, 1992

9. Daming C, Yiwen S, Bin Z, Yajun X, Jia Y, Rui S, et al: Large vestibular schwannoma resection through the suboccipital retrosigmoid keyhole approach. J Craniofac Surg 25:463-468, 2014

10. Darwish BS, Bird PA, Goodisson DW, Bonkowski JA, MacFarlane MR: Facial nerve function and hearing preservation after retrosigmoid excision of vestibular schwannoma: Christchurch Hospital experience with 97 patients. ANZ J Surg 75:893-896, 2005

11. Fuentes S, Arkha Y, Pech-Gourg G, Grisoli F, Dufour H, Regis J: Management of large vestibular schwannomas by combined surgical resection and gamma knife radiosurgery. Prog Neurol Surg 21:79-82, 2008

12. Fukuda M, Oishi M, Hiraishi T, Natsumeda M, Fujii Y: Clinicopathological factors related to regrowth of vestibular schwannoma after incomplete resection. J Neurosurg 114:1224-1231, 2011

13. Georges H, Thakur B, Argiris K, Saunders N, Hardwidge C: Subtotal resection of large vestibular schwannoma is an effective treatment. J Neurol Surg B 77:FP-05-05, 2016 (Abstract)

14. Gurgel RK, Dogru S, Amdur RL, Monfared A: Facial nerve outcomes after surgery for large vestibular schwannomas: do surgical approach and extent of resection matter? Neurosurg Focus 33(3):E16, 2012

15. Iorio-Morin C, AlSubaie F, Mathieu D: Safety and efficacy of Gamma Knife radiosurgery for the management of Koos grade 4 vestibular schwannomas. Neurosurgery 78:521-530, 2016

16. Iwai Y, Yamanaka K, Ishiguro T: Surgery combined with radiosurgery of large acoustic neuromas. Surg Neurol 59:283-291, 2003

17. Jung S, Kang SS, Kim TS, Kim HJ, Jeong SK, Kim SC, et al: Current surgical results of retrosigmoid approach in extralarge vestibular schwannomas. Surg Neurol 53:370-378, 2000

18. Lanman TH, Brackmann DE, Hitselberger WE, Subin B: Report of 190 consecutive cases of large acoustic tumors (vestibular schwannoma) removed via the translabyrinthine approach. J Neurosurg 90:617-623, 1999

19. Lee SH, Willcox TO, Buchheit WA: Current results of the surgical management of acoustic neuroma. Skull Base 12:189-195, 2002 
20. Liu SW, Jiang W, Zhang HQ, Li XP, Wan XY, Emmanuel B, et al: Intraoperative neuromonitoring for removal of large vestibular schwannoma: facial nerve outcome and predictive factors. Clin Neurol Neurosurg 133:83-89, 2015

21. Mamikoglu B, Wiet RJ, Esquivel CR: Translabyrinthine approach for the management of large and giant vestibular schwannomas. Otol Neurotol 23:224-227, 2002

22. Myrseth E, Møller P, Pedersen PH, Lund-Johansen M: Vestibular schwannoma: surgery or gamma knife radiosurgery? A prospective, nonrandomized study. Neurosurgery 64:654-663, 2009

23. Nedzelski JM, Schessel DA, Pfleiderer A, Kassel EE, Rowed DW: Conservative management of acoustic neuromas. Otolaryngol Clin North Am 25:691-705, 1992

24. O'Reilly B, Murray CD, Hadley DM: The conservative management of acoustic neuroma: a review of forty-four patients with magnetic resonance imaging. Clin Otolaryngol Allied Sci 25:93-97, 2000

25. Pan HC, Sheehan J, Sheu ML, Chiu WT, Yang DY: Intracapsular decompression or radical resection followed by Gamma Knife surgery for patients harboring a large vestibular schwannoma. J Neurosurg 117 Suppl:69-77, 2012

26. Pollock BE, Driscoll CL, Foote RL, Link MJ, Gorman DA, Bauch CD, et al: Patient outcomes after vestibular schwannoma management: a prospective comparison of microsurgical resection and stereotactic radiosurgery. Neurosurgery 59:77-85, 2006

27. Pollock BE, Lunsford LD, Kondziolka D, Flickinger JC, Bissonette DJ, Kelsey SF, et al: Outcome analysis of acoustic neuroma management: a comparison of microsurgery and stereotactic radiosurgery. Neurosurgery 36:215-229, 1995

28. Propp JM, McCarthy BJ, Davis FG, Preston-Martin S: Descriptive epidemiology of vestibular schwannomas. Neuro Oncol 8:1-11, 2006

29. Raftopoulos C, Abu Serieh B, Duprez T, Docquier MA, Guerit JM: Microsurgical results with large vestibular schwannomas with preservation of facial and cochlear nerve function as the primary aim. Acta Neurochir (Wien) 147:697-706, 2005

30. Raslan AM, Liu JK, McMenomey SO, Delashaw JB Jr: Staged resection of large vestibular schwannomas. J Neurosurg 116:1126-1133, 2012

31. Régis J, Carron R, Park MC, Soumare O, Delsanti C, Thomassin JM, et al: Wait-and-see strategy compared with proactive Gamma Knife surgery in patients with intracanalicular vestibular schwannomas. J Neurosurg 113 Suppl:105-111, 2010

32. Régis J, Pellet W, Delsanti C, Dufour H, Roche PH, Thomassin JM, et al: Functional outcome after gamma knife surgery or microsurgery for vestibular schwannomas. J Neurosurg 97:1091-1100, 2002

33. Roland JT, Fishman AJ, Golfinos JG, Cohen N, Alexiades G, Jackman AH, et al: Cranial nerve preservation in surgery for large acoustic neuromas. Skull Base 14:85-90, 2004

34. Samii M, Gerganov VM, Samii A: Functional outcome after complete surgical removal of giant vestibular schwannomas. J Neurosurg 112:860-867, 2010

35. Sanna M, Taibah A, Russo A, Falcioni M, Agarwal M: Perioperative complications in acoustic neuroma (vestibular schwannoma) surgery. Otol Neurotol 25:379-386, 2004

36. Schessel DA, Nedzelski JM, Rowed D, Feghali JG: Pain after surgery for acoustic neuroma. Otolaryngol Head Neck Surg 107:424-429, 1992

37. Silva J, Cerejo A, Duarte F, Silveira F, Vaz R: Surgical removal of giant acoustic neuromas. World Neurosurg 77:731-735, 2012

38. Smouha EE, Yoo M, Mohr K, Davis RP: Conservative management of acoustic neuroma: a meta-analysis and proposed treatment algorithm. Laryngoscope 115:450-454, 2005

39. Stangerup SE, Caye-Thomasen P, Tos M, Thomsen J: The natural history of vestibular schwannoma. Otol Neurotol 27:547-552, 2006

40. Sughrue ME, Kaur R, Rutkowski MJ, Kane AJ, Kaur G, Yang I, et al: Extent of resection and the long-term durability of vestibular schwannoma surgery. J Neurosurg 114:12181223,2011

41. Teo M, Zhang M, Li A, Thompson PA, Tayag AT, Wallach J, et al: The outcome of hypofractionated stereotactic radiosurgery for large vestibular schwannomas. World Neurosurg 93:398-409, 2016

42. Tschudi DC, Linder TE, Fisch U: Conservative management of unilateral acoustic neuromas. Am J Otol 21:722-728, 2000

43. van de Langenberg R, Hanssens PE, van Overbeeke JJ, Verheul JB, Nelemans PJ, de Bondt BJ, et al: Management of large vestibular schwannoma. Part I. Planned subtotal resection followed by Gamma Knife surgery: radiological and clinical aspects. J Neurosurg 115:875-884, 2011

44. van de Langenberg R, Hanssens PE, Verheul JB, van Overbeeke JJ, Nelemans PJ, Dohmen AJ, et al: Management of large vestibular schwannoma. Part II. Primary Gamma Knife surgery: radiological and clinical aspects. J Neurosurg 115:885-893, 2011

45. Veronezi RJ, Fernandes YB, Borges G, Ramina R: Long-term facial nerve clinical evaluation following vestibular schwannoma surgery. Arq Neuropsiquiatr 66:194-198, 2008

46. Wait SD, Gazzeri R, Galarza M, Teo C: Simple, effective, supine positioning for the retrosigmoid approach. Minim Invasive Neurosurg 54:196-198, 2011

47. Williams BJ, Xu Z, Salvetti DJ, McNeill IT, Larner J, Sheehan JP: Gamma Knife surgery for large vestibular schwannomas: a single-center retrospective case-matched comparison assessing the effect of lesion size. J Neurosurg 119:463-471, 2013

48. Wu H, Sterkers JM: Translabyrinthine removal of large acoustic neuromas in young adults. Auris Nasus Larynx 27:201-205, 2000

49. Yamakami I, Uchino Y, Kobayashi E, Yamaura A, Oka N: Removal of large acoustic neurinomas (vestibular schwannomas) by the retrosigmoid approach with no mortality and minimal morbidity. J Neurol Neurosurg Psychiatry 75:453-458, 2004

50. Zeiler FA, Bigder M, Kaufmann A, McDonald PJ, Fewer D, Butler J, et al: Gamma knife radiosurgery for large vestibular schwannomas: a Canadian experience. Can J Neurol Sci 40:342-347, 2013

51. Zhao X, Wang Z, Ji Y, Wang C, Yu R, Ding X, et al: Longterm facial nerve function evaluation following surgery for large acoustic neuromas via retrosigmoid transmeatal approach. Acta Neurochir (Wien) 152:1647-1652, 2010

\section{Disclosures}

Charles Teo is a consultant for Aesculap.

\section{Author Contributions}

Conception and design: Hoshide, C Teo. Acquisition of data: all authors. Analysis and interpretation of data: all authors. Drafting the article: all authors. Critically revising the article: Hoshide, Faulkner, C Teo. Reviewed submitted version of manuscript: Hoshide, Faulkner, C Teo. Approved the final version of the manuscript on behalf of all authors: Hoshide. Statistical analysis: Hoshide, C Teo. Administrative/technical/material support: Hoshide, Faulkner, C Teo. Study supervision: Hoshide, C Teo.

\section{Correspondence}

Reid Hoshide: University of California, San Diego, CA. rhoshide@ucsd.edu. 